\title{
中国北方农牧交错带气候变化特点及未来趋势 基于观测和模拟资料的综合分析
}

\author{
方梓行 ${ }^{1,2}$, 何春阳 ${ }^{1,2}$, 刘志锋 ${ }^{1,2}$, 赵媛媛 ${ }^{3}$, 杨延杰 ${ }^{1,2}$
}

(1. 北京师范大学地表过程与资源生态国家重点实验室, 人与环境系统可持续研究中心, 北京 100875 ;

2. 北京师范大学地理科学学部自然资源学院, 土地资源与区域发展研究中心, 北京 100875 ;

3. 北京林业大学水土保持学院, 北京 100083)

\begin{abstract}
摘要：中国北方农牧交错带是中国生态文明建设的一个重点地区。准确评估其气候变化趋势 对于该区域可持续发展至关重要。本文的研究目的是在揭示 1971-2015年气候变化特征的基 础上, 分析区域2006-2050年气候变化趋势。为此, 本文综合观测和模拟数据分析了区域 19712015年的历史气候变化以及 2006-2050年的未来气候变化。研究发现: 1971-2015年, 中国北方 农牧交错带气候变化呈暖干化趋势, 年均气温的增长速率为 $0.39{ }^{\circ} \mathrm{C} / 10 \mathrm{a}$, 年降水量的变化速率 为 $-4.60 \mathrm{~mm} / 10 \mathrm{a} 。 2006-2050$ 年, 区域气候变化将呈暖湿化趋势, 区域总体年均气温的增长速 率为 $0.20 \sim 0.50{ }^{\circ} \mathrm{C} / 10 \mathrm{a}$, 年降水量的变化速率为 $1.49 \sim 15.59 \mathrm{~mm} / 10 \mathrm{a}$ 。同时, 如果不有效控制温 室气体排放, 区域气候系统的不稳定性将加剧。2006-2050年, 随着温室气体排放浓度的不断 增加, 区域增温速率从 $0.25^{\circ} \mathrm{C} / 10$ a 增长至 $0.48{ }^{\circ} \mathrm{C} / 10$ a, 降水变化速率从 $3.97 \mathrm{~mm} / 10$ a 增长至 $14.58 \mathrm{~mm} / 10 \mathrm{a}$ 。因此, 需要高度重视中国北方农牧交错带气候变化的减缓和适应问题, 以促进 该区域的可持续发展。
\end{abstract}

关键词: 气候变化; 中国北方农牧交错带;观测资料;模拟数据;减缓和适应

中国北方农牧交错带是指将中国东北、华北农区与天然草地牧区分割的生态过渡 带，是中国可持续发展和生态文明建设重点关注区域之一 ${ }^{[1,2]}$ 。该区域对气候变化和人为 干扰非常敏感。近几十年来，在气候变化和人类活动的双重影响下，区域干早灾害频 发, 极端气候事件增多, 生态环境退化明显 ${ }^{[3-5]}$ 。因此, 准确地认识和理解中国北方农牧 交错带的气候变化趋势，对于有效应对气候变化、实现该区域可持续发展具有重要意义。

当前, 已有研究主要采用气候观测资料和气候模式资料两类数据分析中国北方农牧 交错带的气候变化趋势。气候观测资料能够反映过去气候变化的趋势。例如，李敏敏等 ${ }^{[6]}$ 利用气象观测资料，分析区域 1961-2010年气候变化趋势。杜华明等 ${ }^{[5]}$ 利用气象观测资 料，分析区域 1961-2012 年气候变化趋势。气候模式资料能够模拟未来气候变化的趋势。 例如, 间冠华等 ${ }^{[7]}$ 基于全球海气耦合模式嵌套区域模式, 分析区域 2001-2030 年气候变化 趋势。然而, 受模式模拟能力、温室气体排放强度等因素的影响, 采用单一模式和单一 情景分析未来气候变化, 模拟结果具有较大的不确定性 ${ }^{[8,9]}$ 。因此, 继续深人分析该区域 的气候变化趋势仍然是十分必要的。

收稿日期：2018-12-26; 修订日期：2019-02-18

基金项目：国家自然科学基金项目（41871185，41621061）

作者简介：方梓行 (1994- ), 男, 浙江宁海人, 博士研究生, 主要从事气候变化与景观可持续科学研究。 E-mail: zihangfang@mail.bnu.edu.cn

通讯作者: 何春阳 (1975-), 男, 四川射洪人, 博士, 教授, 主要从事土地利用/覆盖变化、景观可持续科学和城市 可持续科学研究。E-mail: hcy@bnu.edu.cn 
国际耦合模式比较计划第五阶段（The Fifth Phase of the Coupled Model Intercomparison Project, CMIP 5) 气候模式数据是联合国政府间气候变化专门委员会（Intergovernmental Panel on Climate Change, IPCC）第五次评估报告采用的全球气候变化模式评估 数据 ${ }^{[10]}$ 。CMIP 5 模式数据提高了气候模式的模拟和预估能力, 增强了对气候系统变化的 机理性认识，可以更加有效地表征未来气候变化趋势 ${ }^{[10]}$ 。近年来，已有学者基于 CMIP 5 气候模式数据分析了不同地区未来气候变化趋势。比如，胡芩等 ${ }^{\left[{ }^{[1]}\right.}$ 利用 CMIP 5 气候模式 数据分析了青藏高原地区 2006-2100年气候变化趋势。刘彩红等 ${ }^{[2]}$ 基于 CMIP 5 气候模式 数据分析了青海高原地区 2011-2100 年气候变化趋势。吴蔚等 ${ }^{[13]}$ 利用 CMIP 5 气候模式数 据分析了上海市2006-2030年气候变化趋势。

中国区域气候模式数据是由中国国家气候中心以全球气候模式输出结果为初始场和 边界场, 单向嵌套全球气候模式, 模拟得到的中国未来气候变化数据 ${ }^{[14]}$ 。与全球气候模式 相比, 中国区域气候模式能更真实地反映地形强迫, 更精确地描述区域气候变化特征 ${ }^{[15]}$ 。 目前，中国区域气候模式数据已经开始应用于中国不同地区未来气候变化的研究中。比 如，He 等 ${ }^{[16]}$ 利用中国区域气候模式数据探究了京津唐地区 2009-2030年气候变化趋势。 景承等 ${ }^{\left[{ }^{177}\right.}$ 基于中国区域气候模式数据预测了中国 2016-2050年气候变化趋势。但目前综合 利用 CMIP 5 气候模式数据和中国区域气候模式数据, 对中国典型地区气候变化趋势的深 人分析和理解还比较少见。

因此，本研究的基本目的是在历史观测资料的基础上，综合利用全球气候模式模拟 数据和中国区域气候模式模拟数据来认识和理解中国北方农牧交错带气候变化趋势。将 首先利用观测资料，分析该区域1971-2015 年区域气候变化特征。然后综合利用全球气候 模式和区域气候模式数据，揭示不同温室气体排放路径下，区域2006-2050年气候变化的 趋势。研究结果有利于全面认识中国北方农牧交错带气候变化趋势, 为该区域气候变化 的减缓和适应提供依据。

\section{1 研究方法与数据来源}

\section{1 研究区概况}

研究区位于 $100^{\circ} \sim 125^{\circ} \mathrm{E} 、 34^{\circ} \sim 49^{\circ} \mathrm{N}$ 之间, 总面积为 72.6 万 $\mathrm{km}^{2}$, 占中国国土总面积 的 $8.11 \%$ （图 1)。该区域是东北、华北平原和黄土高原向内蒙古高原、青藏高原的过渡 带, 海拔由东北向西南递增, 最低处不及 $200 \mathrm{~m}$ ，最高处接近 $4500 \mathrm{~m}^{[18]}$ 。区域地处半湿 润大陆性季风气候向干旱典型大陆性气候过渡地区, 年平均气温 $2 \sim 8{ }^{\circ} \mathrm{C}$, 年平均降水量 250 500 mm, 中心地带降水量为 400 450 $\mathrm{mm}^{[1,2,19]}$ 。

参考史培军等 ${ }^{[20]}$ 对中国 1961-2010年气候变化特征的研究，依据气温和降水的变化特 征，将该区域进一步划分为西部区、中西部区、中东部区和东部区四个亚区（图 1)。西 部区位于北方农牧交错带西南部, 平均气温波动为 $0.234{ }^{\circ} \mathrm{C}$, 平均降水波动为 $13.0 \mathrm{~mm}$ 。 中西部区水系密度较低, 平均气温波动为 $0.225{ }^{\circ} \mathrm{C}$, 平均降水波动为 $32.7 \mathrm{~mm}$ 。中东部区 水系密度较低, 气候温暖干燥, 平均气温波动为 $0.245{ }^{\circ} \mathrm{C}$, 平均降水波动为 $46.3 \mathrm{~mm}$ 。东 部区水系密度低, 气候温暖干燥, 平均气温波动为 $0.210{ }^{\circ} \mathrm{C}$, 平均降水波动为 $39.5 \mathrm{~mm}$ 。

\section{2 数据}

使用的气象观测数据来源于中国气象数据网（http://data.cma.cn/data/detail/dataCode）, 
包括位于北方农牧交错带及其周边 92 个站点 1975-2015 年的逐月温度和降水数据（图 1)。

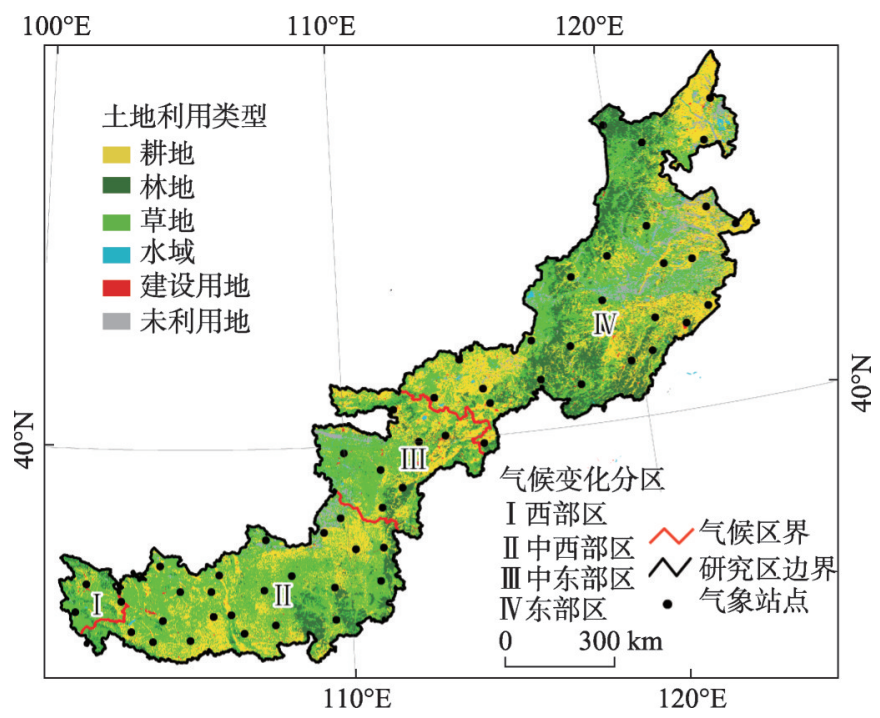

图 1 研究区

Fig. 1 Map showing the study area

使用的气候模式模拟数据包括典型浓度路径（Representative concentration pathway， RCP） 2.6、RCP 4.5 和 RCP 8.5 三种排放情景下 2006-2050 年全球气候模式数据和区域气 候模式数据。使用的全球气候模式数据主要有 7 种模式，分别为 BNU、CanESM 2、CCSM 4、IPSL-CM5A-LR、MPI-ESM-LR、MRI-CGCM 3 以及 NorESM1-M，这些模式数据 的空间分辨率各不相同（表 1)。它们来源于 PCMDI（Program for Climate Model Diagnosis and Intercomparison) 发布的 WCRP（The World Climate Research Programme） CMIP 5 气候模式数据（https://esgf-node.llnl.gov/search/cmip5）。使用的区域气候模式数据是由 中国国家气候中心发布的基于区域气候模式 $\mathrm{RegCM} 4.0$ 模拟得到的长期气候变化数据, 来源于中国地区气候变化预估数据网（http://www.climatechange-data.cn/en/，表 1）。

气候模式数据中，RCP 2.6 情景表示未来 100 年温室气体浓度先上升再下降最后达到 稳定，2100年辐射强迫小于 $2.6 \mathrm{~W} / \mathrm{m}^{2}$ 的路径形式。RCP 4.5 情景表示未来 100 年温室气体 浓度先上升, 然后上升的趋势逐渐减缓, 最后趋于稳定, 2100 年辐射强迫稳定在 $4.5 \mathrm{~W} / \mathrm{m}^{2}$

表 1 所用全球与区域气候模式基本信息

Table 1 The information about global climate model and regional climate model

\begin{tabular}{|c|c|c|c|c|c|}
\hline 模式类型 & 模式名称 & 国家 & 研究机构 & 空间分辨率/( $\left.{ }^{\circ}\right)$ & 参考文献 \\
\hline \multirow[t]{7}{*}{ 全球气候模式 } & $\mathrm{BNU}$ & 中国 & 北京师范大学 & $2.8125 \times 2.8125$ & 吴其重等 ${ }^{[22]}$ \\
\hline & CanESM 2 & 加拿大 & CCCma & $2.8125 \times 2.8125$ & Chylek 等 ${ }^{[23]}$ \\
\hline & $\mathrm{CCSM} 4$ & 美国 & NCAR & $0.9375 \times 1.25$ & Peacock $^{[24]}$ \\
\hline & IPSL-CM5A-LR & 法国 & IPSL & $1.875 \times 3.75$ & Dufresne 等 ${ }^{[25]}$ \\
\hline & MPI-ESM-LR & 德国 & MPI & $1.875 \times 1.875$ & Stevens 等 ${ }^{[26]}$ \\
\hline & MRI-CGCM3 & 日本 & MRI & $1.125 \times 1.125$ & Yukimoto 等 ${ }^{[27]}$ \\
\hline & NorESM1-M & 挪威 & $\mathrm{NCC}$ & $1.875 \times 2.5$ & Bentsen 等 ${ }^{[28]}$ \\
\hline 区域气候模式 & RegCM 4.0 & 中国 & 国家气候中心 & $1 \times 1$ & Giorgi 等 ${ }^{[29]}$ \\
\hline
\end{tabular}


的路径形式。 RCP 8.5 情景表示未来 100 年温室气体浓度持续上升，2100年辐射强迫时达 到 $8.5 \mathrm{~W} / \mathrm{m}^{2}$ 的路径形式 ${ }^{[21]}$ 。为了减小周期性振动的干扰, 参考史培军等 ${ }^{[20]}$ 的研究, 对气 象观测数据和气候模式模拟数据进行了 5 年滑动平均处理。气候模式的模拟数据始于

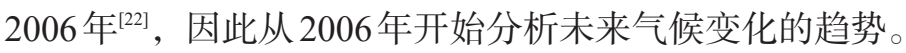

\section{3 整合全球气候模式数据}

参考艾梦池等 ${ }^{\left[{ }^{30]}\right.}$ 及 Egan 等 ${ }^{[31]}$ 的研究，首先采用最邻近法对 7 种全球气候模式数据进 行重采样, 将分辨率统一, 然后逐年求取 7 种模式模拟结果的算数平均值代表全球气候 模式模拟结果。计算过程可表示为:

$$
\bar{X}=\frac{a+b+c+d+e+f+g}{7}
$$

式中: $\bar{X}$ 表示 7 种全球气候模式模拟的年均气温或年降水量的算数平均值; $a \sim g$ 分别表 示 7 种全球气候模式模拟的年均气温 或年降水量。

\section{4 分析区域气候变化趋势}

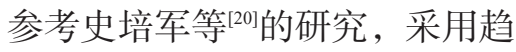
势分析法, 首先利用气象观测数 据, 在全区和气候变化区两个尺度 上揭示区域 1971-2015 气候变化特征 (图 2)。进而利用 RCP 2.6、RCP 4.5 和 RCP 8.5 三种排放情景下 20062050 年全球气候模式数据和区域气 候模式数据, 分析区域未来的气候 变化趋势。趋势分析法可以表示为:

$$
\widehat{y_{j}}=a+b t_{j}
$$

式中: $y$ 为年均气温或年降水量; $t$ 为时间; $a$ 为回归常数; $b$ 为变化趋 势值，利用最小二乘法求取。

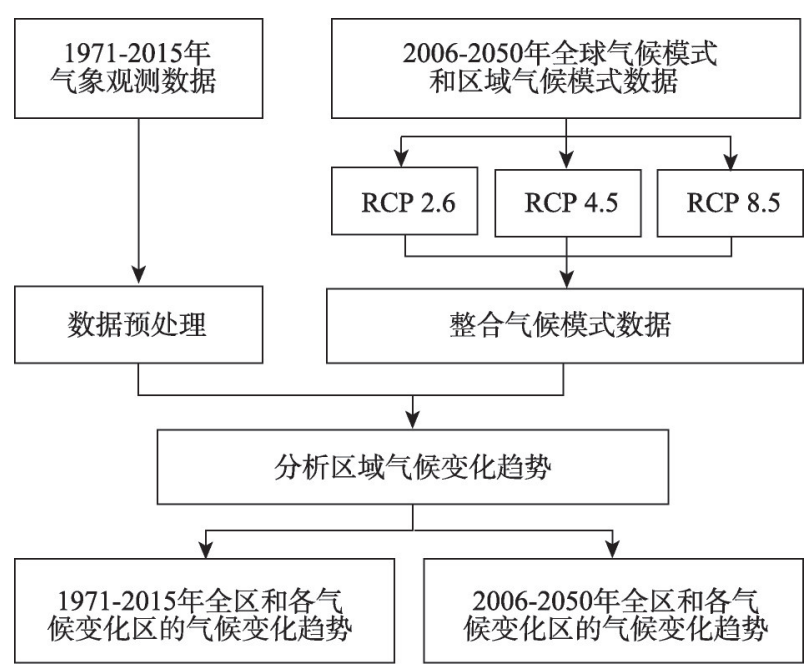

图2 流程图

Fig. 2 Flow chart

$$
\begin{gathered}
a=\frac{1}{41} \sum_{j=1}^{41} y_{j}-b \frac{1}{41} \sum_{j=1}^{41} t_{j}, \\
b=\frac{\sum_{j=1}^{41} y_{j} t_{j}-\frac{1}{41}\left(\sum_{j=1}^{41} y_{j}\right)\left(\sum_{j=1}^{41} t_{j}\right)}{\sum_{j=1}^{41} t_{j}^{2}-\frac{1}{41}\left(\sum_{j=1}^{41} t_{j}\right)^{2}}
\end{gathered}
$$

式中: $b>0$ 表明随时间增加 $y$ 呈上升趋势， $b<0$ 表示随时间增加 $y$ 呈下降趋势。 $b$ 的大小反 映气温或降水的变化速率。

\section{2 结果分析}

\subsection{1-2015 年区域气候变化特征}

1971-2015 年，中国北方农牧交错带整体呈暖干化趋势。全区平均增温速率为 $0.39{ }^{\circ} \mathrm{C} / 10 \mathrm{a}$, 年降水量变化速率为 $-4.70 \mathrm{~mm} / 10 \mathrm{a}$ (图 3)。同时, 气候变化表现出明显的 空间差异。中东部地区暖干化趋势更为剧烈，平均增温速率达到 $0.57{ }^{\circ} \mathrm{C} / 10 \mathrm{a}$, 年降水量 

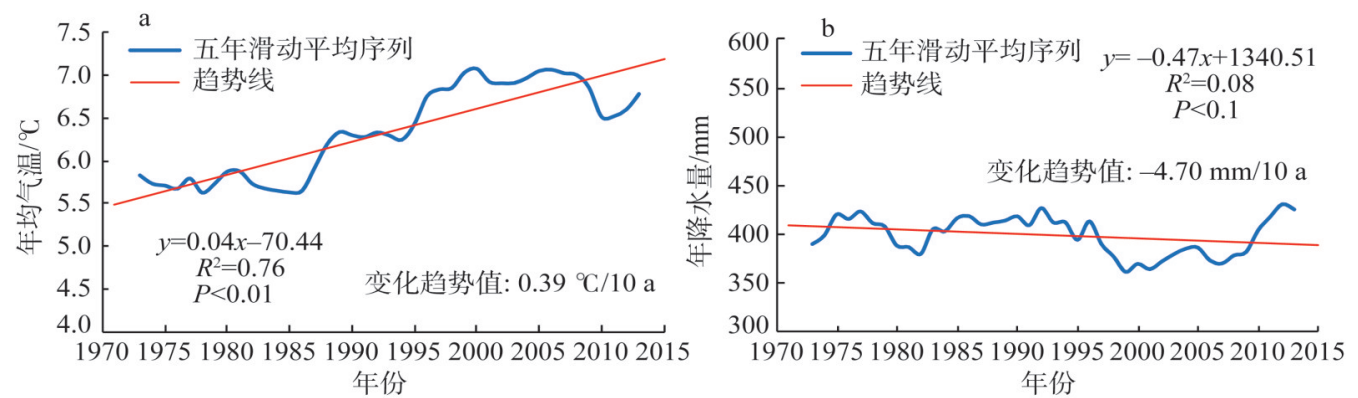

图 3 1971-2015年区域气候变化

Fig. 3 The regional climate change from 1971 to 2015

变化速率为 $-5.96 \mathrm{~mm} / 10 \mathrm{a}$ 。其次是中西部和东部区, 平均增温速率分别为 $0.38{ }^{\circ} \mathrm{C} / 10 \mathrm{a}$ 和 $0.35^{\circ} \mathrm{C} / 10 \mathrm{a}$ ，年降水量变化速率分别为 $-5.10 \mathrm{~mm} / 10 \mathrm{a}$ 和 $-5.61 \mathrm{~mm} / 10 \mathrm{a}$ 。西部区呈暖湿 化趋势，平均增温速率为 $0.32{ }^{\circ} \mathrm{C} / 10 \mathrm{a}$ ，年降水量变化速率为 $8.03 \mathrm{~mm} / 10 \mathrm{a}$ (图 4)。

\subsection{6-2050 年区域气候变化趋势}

2006-2050年，全球气候模式和中国区域气候模式的模拟结果都显示，中国北方农牧 交错带整体呈暖湿化趋势。在 RCP 2.6 情景下，全球气候模式模拟结果显示，全区平均 增温速率为 $0.30{ }^{\circ} \mathrm{C} / 10 \mathrm{a}$ ，年降水量的变化速率为 $6.44 \mathrm{~mm} / 10 \mathrm{a}$ 。其中，东部地区暖湿化 趋势最强, 平均增温速率为 $0.31^{\circ} \mathrm{C} / 10 \mathrm{a}$, 年降水量的变化速率为 $8.81 \mathrm{~mm} / 10 \mathrm{a}$ 。中西部地 区暖湿化趋势最弱，平均增温速率为 $0.28{ }^{\circ} \mathrm{C} / 10 \mathrm{a}$ ，年降水量的变化速率为 $3.02 \mathrm{~mm} / 10 \mathrm{a}$ （图 5、图 6、表 2)。区域气候模式模拟结果显示，全区平均增温速率为 $0.20{ }^{\circ} \mathrm{C} / 10 \mathrm{a}$, 年 降水量的变化速率为 $1.49 \mathrm{~mm} / 10 \mathrm{a}$ 。气候变化表现出明显的区域差异。中西部区和东部 区呈暖湿化趋势, 平均增温速率分别为 $0.20{ }^{\circ} \mathrm{C} / 10 \mathrm{a}$ 和 $0.20{ }^{\circ} \mathrm{C} / 10 \mathrm{a}$, 年降水量的变化速率分 别为 $3.58 \mathrm{~mm} / 10 \mathrm{a}$ 和 $2.70 \mathrm{~mm} / 10 \mathrm{a}$ (图 5、图6、表2)。西部和中东部地区呈暖干化趋势, 平均增温速率分别为 $0.28{ }^{\circ} \mathrm{C} / 10 \mathrm{a}$ 和 $0.21{ }^{\circ} \mathrm{C} / 10 \mathrm{a}$, 年降水量的变化速率分别为 $-11.20 \mathrm{~mm} / 10 \mathrm{a}$ 和 $-4.27 \mathrm{~mm} / 10 \mathrm{a}$ (图 5、图 6、表 2)。

在 RCP 4.5 情景下，全球气候模式模拟结果显示，全区平均增温速率为 $0.38{ }^{\circ} \mathrm{C} / 10 \mathrm{a}$, 年降水量的变化速率为 $12.74 \mathrm{~mm} / 10 \mathrm{a}$ 。其中, 在中东部地区, 暖湿化趋势最强, 平均增 温速率为 $0.39{ }^{\circ} \mathrm{C} / 10 \mathrm{a}$, 年降水量的变化速率为 $15.44 \mathrm{~mm} / 10 \mathrm{a}$ 。在西部地区, 暖湿化趋势最 弱，平均增温速率为 $0.36{ }^{\circ} \mathrm{C} / 10 \mathrm{a}$ ，年降水量的变化速率为 $5.75 \mathrm{~mm} / 10 \mathrm{a}$ (图 5、图 6、表 2)。 区域气候模式模拟结果显示，全区平均增温速率为 $0.30{ }^{\circ} \mathrm{C} / 10 \mathrm{a}$, 年降水量的变化速率为 $13.79 \mathrm{~mm} / 10 \mathrm{a}$ 。其中, 气候变化也呈现一定的区域差异。西部地区平均增温速率为 $0.26{ }^{\circ} \mathrm{C} / 10 \mathrm{a}$, 年降水量的变化速率为 $13.86 \mathrm{~mm} / 10 \mathrm{a}$; 中西部地区平均增温速率为 $0.33{ }^{\circ} \mathrm{C} / 10 \mathrm{a}$, 年降水量的变化速率为 $6.82 \mathrm{~mm} / 10 \mathrm{a}$; 中东部地区平均增温速率为 $0.29^{\circ} \mathrm{C} / 10 \mathrm{a}$, 年降水量的变化速率为 $21.80 \mathrm{~mm} / 10 \mathrm{a}$; 东部地区平均增温速率为 $0.28{ }^{\circ} \mathrm{C} / 10 \mathrm{a}$ ，年降水量的变化速率为 $19.12 \mathrm{~mm} / 10 \mathrm{a}$ (图 5、图 6、表 2)。

在 RCP 8.5 情景下，全球气候模式模拟结果显示，全区平均增温速率为 $0.50{ }^{\circ} \mathrm{C} / 10 \mathrm{a}$, 年降水量的变化速率为 $13.55 \mathrm{~mm} / 10 \mathrm{a}$ 。其中，西部地区平均增温速率为 $0.50{ }^{\circ} \mathrm{C} / 10 \mathrm{a}$, 年 降水量的变化速率为 $13.10 \mathrm{~mm} / 10 \mathrm{a}$; 中西部地区平均增温速率为 $0.49{ }^{\circ} \mathrm{C} / 10 \mathrm{a}$, 年降水量 的变化速率为 $18.03 \mathrm{~mm} / 10 \mathrm{a}$; 中东部地区平均增温速率为 $0.48{ }^{\circ} \mathrm{C} / 10 \mathrm{a}$, 年降水量的变化 速率为 $12.10 \mathrm{~mm} / 10 \mathrm{a}$; 东部地区平均增温速率为 $0.52{ }^{\circ} \mathrm{C} / 10 \mathrm{a}$, 年降水量的变化速率为 

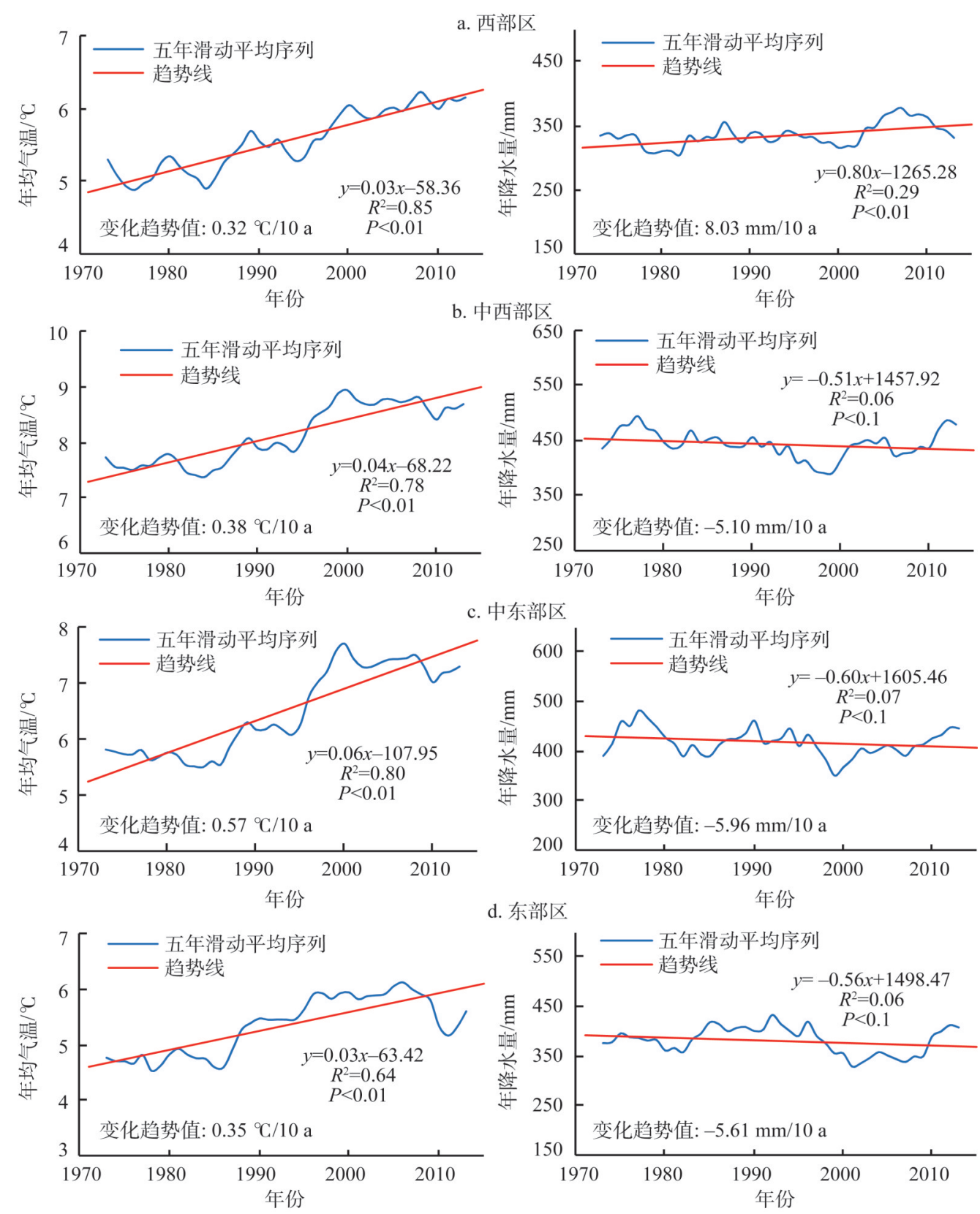

图 4 1971-2015 年区域各气候区气候变化

Fig. 4 The climate change in each climatic area from 1971 to 2015

$11.35 \mathrm{~mm} / 10 \mathrm{a}$ (图 5、图 6、表 2)。区域气候模式模拟结果显示, 全区平均增温速率为 $0.45^{\circ} \mathrm{C} / 10 \mathrm{a}$, 年降水量的变化速率为 $15.59 \mathrm{~mm} / 10 \mathrm{a}$ 。其中, 西部地区暖湿化趋势最强, 平均增温速率为 $0.52{ }^{\circ} \mathrm{C} / 10 \mathrm{a}$ ，年降水量的变化速率为 $21.64 \mathrm{~mm} / 10 \mathrm{a}$ 。中西部地区平均增温 速率为 $0.43{ }^{\circ} \mathrm{C} / 10 \mathrm{a}$, 年降水量的变化速率为 $15.71 \mathrm{~mm} / 10 \mathrm{a}$ 。中东部地区平均增温速率为 $0.43{ }^{\circ} \mathrm{C} / 10 \mathrm{a}$, 年降水量的变化速率为 $15.71 \mathrm{~mm} / 10 \mathrm{a}$ 。东部地区平均增温速率为 $0.46{ }^{\circ} \mathrm{C} / 10 \mathrm{a}$, 年降水量的变化速率为 $10.64 \mathrm{~mm} / 10 \mathrm{a}$ （图 5、图6、表2）。 


\section{3 讨论}

\section{1 该区域气候变化的模拟结果尽管存} 在着一定的不确定性,但基本趋势相同

首先, 发现 7 种全球气候模式模 拟的区域气候变化趋势基本一致。以 RCP 4.5 情景为例, 在温度模拟方面, CanESM 2 模拟的增温速率最大，达到 了 $0.47{ }^{\circ} \mathrm{C} / 10 \mathrm{a}$; MRI-CGCM 3 模拟的增 温速率最小，仅为 $0.30{ }^{\circ} \mathrm{C} / 10 \mathrm{a}$ 。降水 模拟方面，在所有变化速率通过 0.1 显 著性检验的模式中，CanESM 2 模拟的 年降水量变化速率最大，达到了 38.84 $\mathrm{mm} / 10 \mathrm{a} ; \mathrm{CCSM} 4$ 模拟的年降水量变 化速率最小，仅为 $9.38 \mathrm{~mm} / 10 \mathrm{a}$ (表 3 )。 7 种全球气候模式之间的比较发现，增 温速率之差达到了 $0.17{ }^{\circ} \mathrm{C} / 10 \mathrm{a}$, 年降 水量变化速率之差达到 $29.46 \mathrm{~mm} / 10 \mathrm{a}$, 但是所有模式模拟的气候变化趋势均 为暖湿化趋势。

其次，与仅采用单一全球气候模 式的模拟结果相比，综合 7 个全球气 候模式的模拟结果可有效降低不确定 性。利用1971-2005 年各模式的模拟结 果与实际观测值进行比较，发现综合 7 个全球气候模式模拟结果得到的气温 变化趋势与实际状况一致，模拟值与 观测值的 $R^{2}$ 最高，达到了 0.4（表 4）。 综合 7 个全球气候模式模拟结果得到 的降水变化趋势也与观测值一致，模 拟值与观测值的 $R^{2}$ 也最高，为 0.06 （表4）。
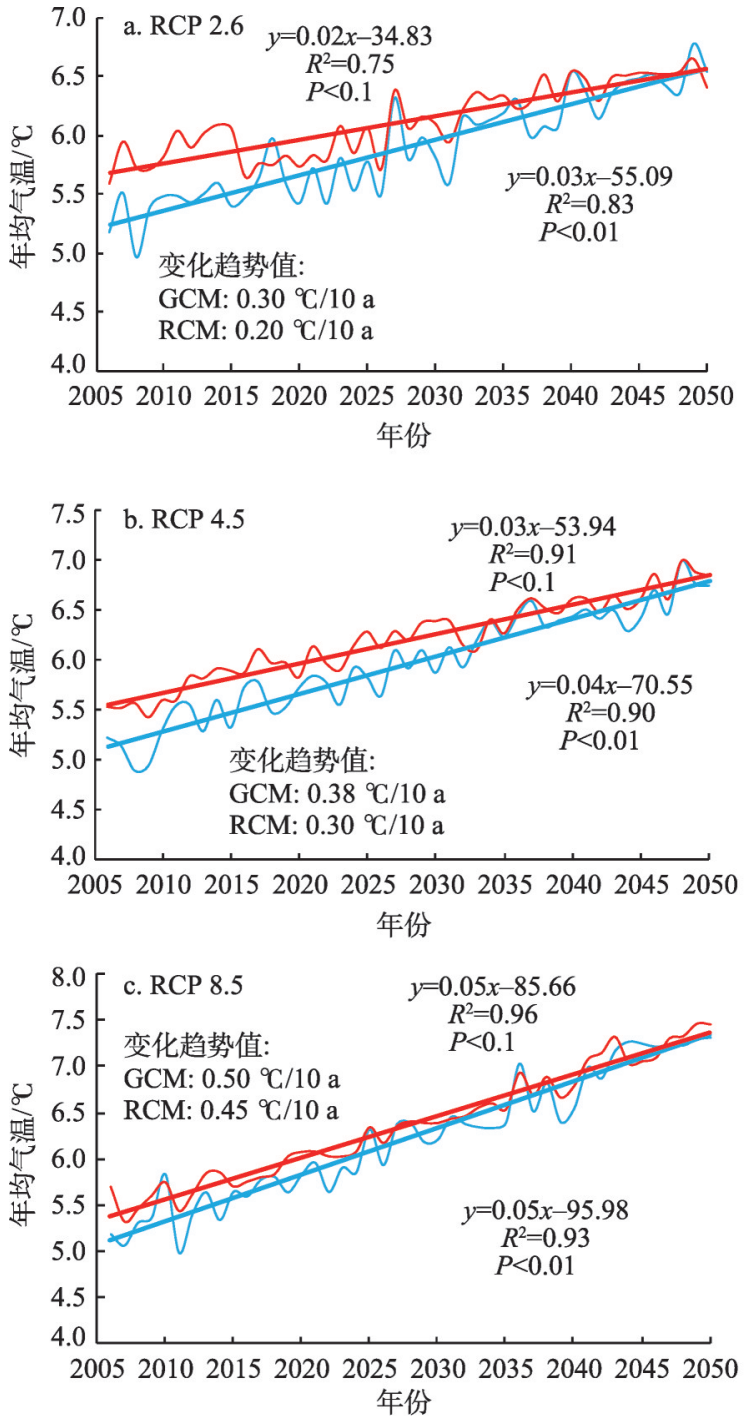

$-\mathrm{GCM}-\mathrm{RCM}$ — 趋势线 $(\mathrm{GCM})$ — 趋势线 $(\mathrm{RCM})$

图 5 不同典型浓度路径下区域2006-2050年 年平均温度变化

Fig. 5 The change of regional mean annual temperature from 2006 to 2050 under different RCPs

而且，还发现全球气候模式的平均模拟结果和区域气候模式的模拟结果也基本一 致。以 RCP 4.5 情景为例, 两类模式模拟得到的结果均为暖湿化趋势。全球气候模式模拟 得到的 2006-2050年增温速率为 $0.38{ }^{\circ} \mathrm{C} / 10 \mathrm{a}$, 年降水量的变化速率为 $13.79 \mathrm{~mm} / 10 \mathrm{a} 。$ 区 域气候模式模拟得到的增温速率为 $0.30{ }^{\circ} \mathrm{C} / 10 \mathrm{a}$ ，年降水量的变化速率为 $12.74 \mathrm{~mm} / 10 \mathrm{a}$ (图7)。

因此，综合利用全球气候模式和区域气候模式的模拟结果，可以得到对该区域未来 气候变化趋势比较可靠的判断。 


\section{2 随着排放浓度增加, 区域暖湿化趋势 将更加明显, 气候系统的不稳定性将加剧}

在 RCP 2.6 情景下，区域 2006-2050 年平均增温速率为 $0.25^{\circ} \mathrm{C} / 10 \mathrm{a}$, 年降水量 的变化速率为 $3.97 \mathrm{~mm} / 10 \mathrm{a}$ 。在 RCP 4.5 情景下，区域2006-2050年平均增温速率 为 $0.34{ }^{\circ} \mathrm{C} / 10 \mathrm{a}$, 年降水量的变化速率为 $13.26 \mathrm{~mm} / 10 \mathrm{a}$ 。在 RCP 8.5 情景下，区 域 2006-2050 年平均增温速率为 $0.48{ }^{\circ} \mathrm{C} /$ $10 \mathrm{a}$, 年降水量的变化速率为 $14.58 \mathrm{~mm} /$ $10 \mathrm{a}$ 。可见，随着排放浓度的增加，区 域气候系统的不稳定性将会增加。区域 2006-2050 年增温速率从 $0.25{ }^{\circ} \mathrm{C} / 10 \mathrm{a}$ 增 长至 $0.48{ }^{\circ} \mathrm{C} / 10 \mathrm{a}$, 增温速率提高了 $0.23{ }^{\circ} \mathrm{C} / 10 \mathrm{a}$ 。降水变化速率从 $3.97 \mathrm{~mm} /$ $10 \mathrm{a}$ 增长至 $14.58 \mathrm{~mm} / 10 \mathrm{a}$, 增长速率提 高了 $10.61 \mathrm{~mm} / 10 \mathrm{a}$ (图 8)。

进一步地, 在西部区, 发现该地区 气候系统稳定性对于排放浓度的变化最 为敏感。在 RCP 2.6 情景下, 西部区 2006-2050 年平均增温速率为 $0.26{ }^{\circ} \mathrm{C} / 10 \mathrm{a}$, 年降水量的变化速率为 $-2.25 \mathrm{~mm} / 10 \mathrm{a}$ 。 在 RCP 4.5 情景下, 该区 2006-2050 年平 均增温速率为 $0.31{ }^{\circ} \mathrm{C} / 10 \mathrm{a}$, 年降水量的 变化速率为 $9.81 \mathrm{~mm} / 10 \mathrm{a}$ 。在 RCP 8.5 下，该区 2006-2050 年平均增温速率为 $0.51{ }^{\circ} \mathrm{C} / 10 \mathrm{a}$, 年降水量的变化速率为 $17.37 \mathrm{~mm} / 10$ a (图 8)。随着排放浓度的 增加, 西部区 2006-2050 年增温速率从 $0.26{ }^{\circ} \mathrm{C} / 10$ a 增长至 $0.51{ }^{\circ} \mathrm{C} / 10 \mathrm{a}$, 增温速 率提高了 $0.25{ }^{\circ} \mathrm{C} / 10 \mathrm{a}$ 。降水变化速率
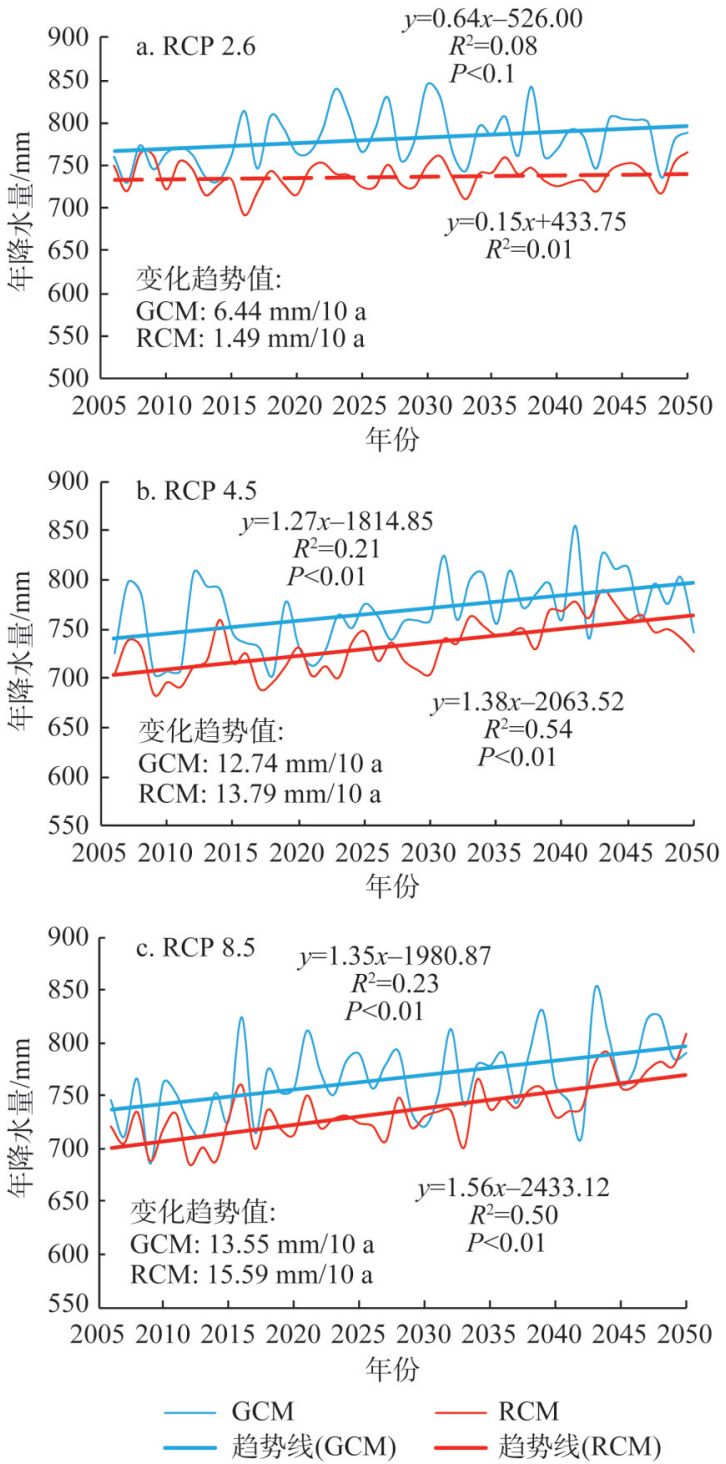

图 6 不同典型浓度路径下区域2006-2050年 年平均降水变化

Fig. 6 The change of regional mean annual precipitation from 2006 to 2050 under different RCPs

从-2.25 mm/10 a增长至 $17.37 \mathrm{~mm} / 10 \mathrm{a}$, 增长速率提高了 $19.62 \mathrm{~mm} / 10 \mathrm{a}$ (图 8 )。

本文的结果与已有研究结果基本一致。比如，张冬峰等 ${ }^{[32]}$ 发现该区域过去自然变率 对降水的影响明显大于温室气体排放的影响，导致该区域过去降水呈下降趋势，但随着 温室气体排放量的持续上升，未来温室气体排放对区域降水的影响将超过自然变率的影 响，导致该区域未来降水呈明显的增长趋势。

由此可见，如果不控制温室气体的排放，区域暖湿化趋势将更加明显，气候系统的 不稳定性将越来越强，气候的变化将会越来越剧烈，所以要高度重视区域气候变化的减 缓和适应问题。一方面需要调整区域产业结构, 优化能源结构, 降低煤炭在能源结构中 
表 2 2006-2050 年区域气候变化

Table 2 The regional climate change from 2006 to 2050

\begin{tabular}{|c|c|c|c|c|c|}
\hline \multirow{3}{*}{ 排放情景 } & \multirow{3}{*}{ 气候分区 } & \multicolumn{4}{|c|}{ 变化趋势值 } \\
\hline & & \multicolumn{2}{|c|}{ 气温/( ${ }^{\circ} \mathrm{C} / 10$ a) } & \multicolumn{2}{|c|}{ 降水 $/(\mathrm{mm} / 10 \mathrm{a})$} \\
\hline & & GCM & $\mathrm{RCM}$ & GCM & RCM \\
\hline \multirow[t]{4}{*}{ RCP 2.6} & 西部区 & $0.23^{*}$ & $0.28^{*}$ & 6.70 & $-11.20^{*}$ \\
\hline & 中西部区 & $0.28^{*}$ & $0.20^{*}$ & 3.02 & 3.58 \\
\hline & 中东部区 & $0.32^{*}$ & $0.21^{*}$ & 5.08 & -4.27 \\
\hline & 东部区 & $0.31^{*}$ & $0.20^{*}$ & $8.81^{*}$ & 2.70 \\
\hline \multirow[t]{4}{*}{$\mathrm{RCP} 4.5$} & 西部区 & $0.36^{*}$ & $0.26^{*}$ & 5.75 & $13.86^{*}$ \\
\hline & 中西部区 & $0.39^{*}$ & $0.33^{*}$ & 6.47 & $6.82^{*}$ \\
\hline & 中东部区 & $0.39^{*}$ & $0.29^{*}$ & $15.44^{*}$ & $21.80^{*}$ \\
\hline & 东部区 & $0.37^{*}$ & $0.28^{*}$ & $16.12^{*}$ & $19.12^{*}$ \\
\hline \multirow[t]{4}{*}{ RCP 8.5} & 西部区 & $0.50^{*}$ & $0.52^{*}$ & $13.10^{*}$ & $21.64^{*}$ \\
\hline & 中西部区 & $0.49^{*}$ & $0.45^{*}$ & $18.03^{*}$ & $17.36^{*}$ \\
\hline & 中东部区 & $0.48^{*}$ & $0.43^{*}$ & $12.10^{\circ}$ & $15.71^{*}$ \\
\hline & 东部区 & $0.42^{*}$ & $0.46^{*}$ & $11.35^{*}$ & $10.64^{*}$ \\
\hline
\end{tabular}

注: "表示通过 0.1 水平的显著性检验，下同。

表 37 种全球气候模式模拟结果比较

Table 3 The comparison of seven global climate models

\begin{tabular}{lcccc}
\hline \multicolumn{1}{c}{ 模式 } & 多年平均气温 $/{ }^{\circ} \mathrm{C}$ & 气温变化速率 $/\left({ }^{\circ} \mathrm{C} / 10 \mathrm{a}\right)$ & 多年平均降水量 $/ \mathrm{mm}$ & 降水变化速率 $/(\mathrm{mm} / 10 \mathrm{a})$ \\
\hline BNU & 6.73 & $0.36^{*}$ & 1143.08 & -10.35 \\
CanESM 2 & 8.71 & $0.47^{*}$ & 886.30 & $38.84^{*}$ \\
CCSM 4 & 5.91 & $0.33^{*}$ & 766.64 & $9.38^{*}$ \\
IPSL-CM5A-LR & 3.66 & $0.45^{*}$ & 705.27 & $15.65^{*}$ \\
MPI-ESM-LR & 7.96 & $0.32^{*}$ & 864.82 & -2.30 \\
MRI-CGCM 3 & 5.16 & $0.30^{*}$ & 415.91 & $15.03^{*}$ \\
NorESM1-M & 4.34 & $0.40^{*}$ & 810.67 & $17.88^{*}$ \\
\hline
\end{tabular}

表 4 全球气候模式模拟结果的可靠性评价

Table 4 The reliability assessment of global climate models

\begin{tabular}{lccccc}
\hline \multirow{2}{*}{ 模式 } & \multicolumn{2}{c}{ 温度 } & & \multicolumn{2}{c}{ 降水 } \\
\cline { 2 - 3 } \cline { 5 - 6 } BNU & Slope $/\left({ }^{\circ} \mathrm{C} / 10 \mathrm{a}\right)$ & $R^{2}$ & Slope/(mm/10 a) & 0.01 \\
CanESM2 & 0.43 & 0.20 & 12.06 & -5.78 & 0.002 \\
CCSM4 & 0.38 & 0.24 & 7.37 & 0.03 \\
IPSL-CM5A-LR & 0.20 & 0.16 & 5.32 & 0.01 \\
MPI-ESM-LR & 0.39 & 0.22 & -16.83 & 0.06 \\
MRI-CGCM3 & 0.25 & 0.17 & -12.49 & 0.002 \\
NorESM1-M & 0.20 & 0.06 & 4.35 & 0.03 \\
多模式平均值 & 0.37 & 0.41 & -0.86 & 0.06 \\
\hline
\end{tabular}

的比例，加速开发风能和太阳能等清洁能源，以降低温室气体排放浓度，减缓气候变 化。另一方面需要将适应气候变化纳人区域经济建设和社会发展规划中，尤其要考虑区 域热量条件和降水等气候要素长期变化趋势对作物、牧草等的影响 ${ }^{[33]}$, 注意区域极端干 旱和极端暴雨等气象灾害的综合风险防范 ${ }^{[34]}$ 。 


\section{4 结论}

1971-2015 年，中国北方农牧交 错带主要呈现暖干化趋势。区域平均 增温速率为 $0.39{ }^{\circ} \mathrm{C} / 10 \mathrm{a}$, 年降水量变 化速率为 $-4.60 \mathrm{~mm} / 10 \mathrm{a}$ 。在该区域 的中东部，暖干化趋势更加明显，平 均增温速率达到了 $0.57{ }^{\circ} \mathrm{C} / 10 \mathrm{a}$ ，年降 水量变化速率为 $-5.96 \mathrm{~mm} / 10 \mathrm{a}$ 。但 西部地区呈暖湿化，平均增温速率 为 $0.32{ }^{\circ} \mathrm{C} / 10 \mathrm{a}$, 年降水量变化速率 为 $8.03 \mathrm{~mm} / 10 \mathrm{a}$ 。

2006-2050 年，中国北方农牧交 错带整体呈现暖湿化趋势。在 RCP 2.6 情景下，7种全球气候模式下模拟 的平均增温速率为 $0.30{ }^{\circ} \mathrm{C} / 10 \mathrm{a}$, 年降 水量变化速率为 $6.44 \mathrm{~mm} / 10 \mathrm{a}$ 。区域 气候模式下模拟的平均增温速率为 $0.20^{\circ} \mathrm{C} / 10 \mathrm{a}$ ，年降水量变化速率为 $1.49 \mathrm{~mm} / 10 \mathrm{a}$ 。在 RCP 4.5 情景下， 7 种全球气候模式下模拟的平均增温速 率为 $0.38{ }^{\circ} \mathrm{C} / 10 \mathrm{a}$, 年降水量变化速率 为 $12.74 \mathrm{~mm} / 10 \mathrm{a} 。$ 区域气候模式下 模拟的平均增温速率为 $0.30{ }^{\circ} \mathrm{C} / 10 \mathrm{a}$, 年降水量变化速率为 $13.79 \mathrm{~mm} / 10 \mathrm{a}$ 。 RCP 8.5 情景下，7种全球气候模式下 模拟的平均增温速率为 $0.50{ }^{\circ} \mathrm{C} / 10 \mathrm{a}$, 年降水量变化速率为 $13.55 \mathrm{~mm} / 10 \mathrm{a}$ 。 区域气候模式下模拟的平均增温速 率为 $0.45{ }^{\circ} \mathrm{C} / 10 \mathrm{a}$, 年降水量变化速 率为 $15.59 \mathrm{~mm} / 10 \mathrm{a}$ 。

随着温室气体排放浓度的增 加，中国北方农牧交错带未来暖湿 化趋势将更加明显, 气候系统的不 稳定性将加剧。2006-2050 年, 从 RCP 2.6 情景到 RCP 8.5 情景，区域 增温速率从 $0.25{ }^{\circ} \mathrm{C} / 10$ a 增长至 $0.48{ }^{\circ} \mathrm{C} / 10 \mathrm{a}$, 降水增加速率从 3.97 $\mathrm{mm} / 10$ a 增长至 $14.58 \mathrm{~mm} / 10 \mathrm{a}$ 。因此, 需要高度重视区域气候变化的减缓和适应问题。
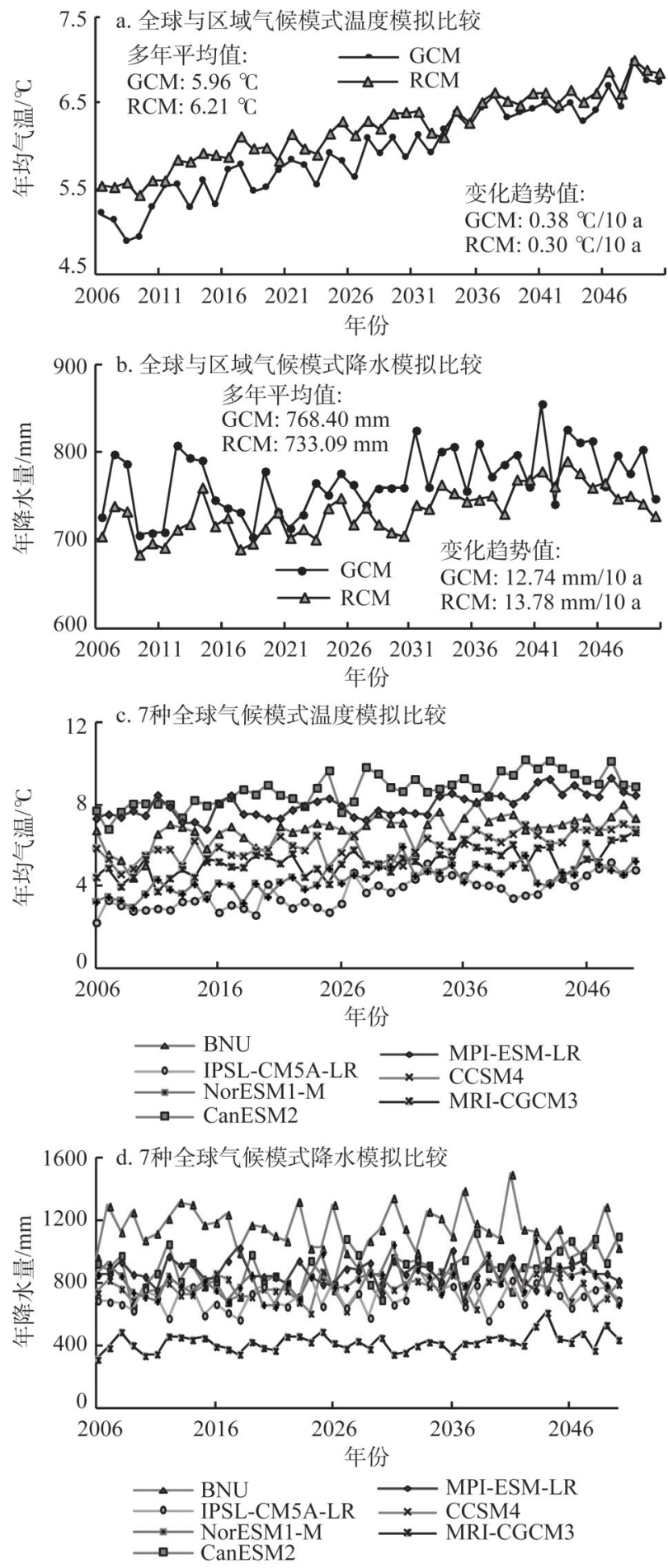

图 7 不同气候模式模拟结果比较

Fig. 7 The comparison of results from different climate models 


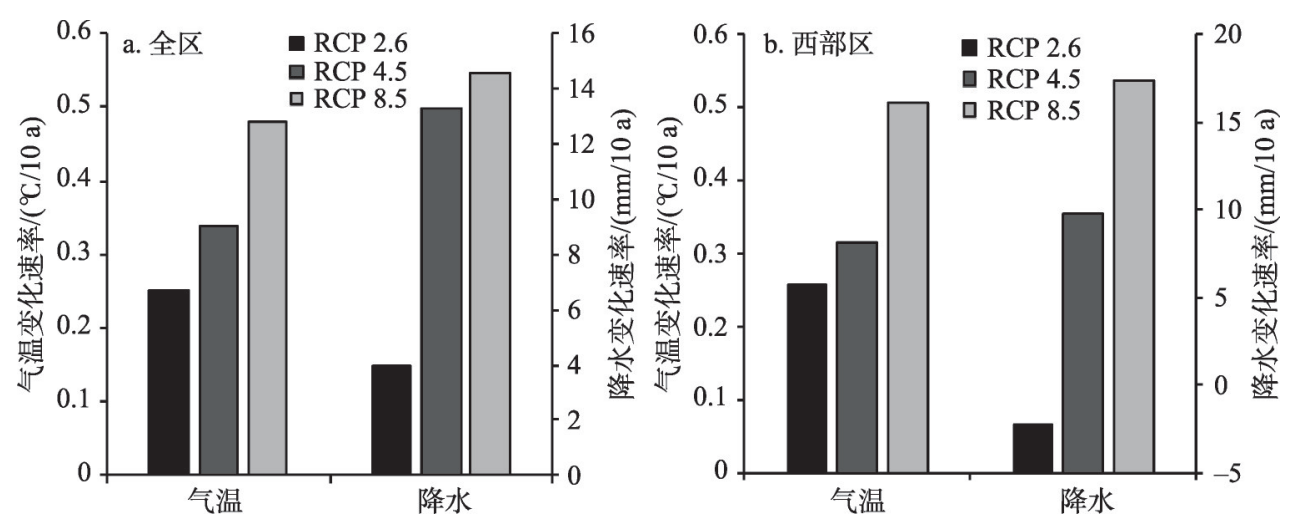

注：基于全球气候模式模拟结果与区域气候模式模拟结果的平均值制图。

图 8 不同排放情景下的气候变化结果比较

Fig. 8 The comparison of climate change under different RCPs

\section{参考文献(References):}

[1] 王静爱, 徐霞, 刘培芳. 中国北方农牧交错带土地利用与人口负荷研究. 资源科学, 1999, 21(5): 19-24. [WANG J A, XU X, LIU P F. Land use and land carrying capacity in ecotone between agriculture and animal husbandry in Northern China. Resources Science, 1999, 21(5): 19-24.]

[2] 史培军, 李晓兵, 王静爱, 等. 中国北方农牧交错带土地利用时空格局与优化模拟. 北京: 科学出版社, 2009. [SHI P J, LI X B, WANG J A, et al. Dynamic Simulation on the Optimal Patterns of Land Use Change for the Farming-pastoral Zone in Northern China. Beijing: Science Press, 2009.]

[3] 李文龙, 石育中, 鲁大铭, 等. 北方农牧交错带干旱脆弱性时空格局演变. 自然资源学报, 2018, 33(9): 1599-1612. [LI W L, SHI Y Z, LU D M, et al. The spatio-temporal evolution of drought vulnerability in the ecotone between agriculture and animal husbandry in the north of China. Journal of Natural Resources, 2018, 33(9): 1599-1612.]

[4] 刘瞳, 黄河清, 闻慧敏, 等. 北方农牧交错区降水过程的持续性特征与干旱发生趋势. 资源科学, 2012, 34(5): 940947. [LIU T, HUANG H Q, YAN H M, et al. The persistence of precipitation series and the trend of drought in Northern Agro-pastoral Zone. Resources Science, 2012, 34(5): 940-947.]

[5] 杜华明, 延军平, 王鹏涛. 北方农牧交错带干旱灾害及其对暖干气候的响应. 干旱区资源与环境, 2015, 29(1): 124128. [DU H M, YAN J P, WANG P T. The drought disaster and its response to the warming-drying climate in the farming-pastoral ecotones in Northern China. Journal of Arid Land Resources and Environment, 2015, 29(1): 124-128.]

[6] 李敏敏, 延军平, 丁彩霞. 北方农牧交错带气候变化与旱涝响应特征. 水土保持通报, 2014, 34(5): 304-308. [LI M M, YAN J P, DING C X. Climate change and response characteristics of drought and flood in farming-pastoral ecotone of Northern China. Bulletin of Soil and Water Conservation, 2014, 34(5): 304-308.]

[7] 间冠华, 李巧萍, 吕冬红. 中国北方农牧交错带气候变化特征及未来趋势. 南京气象学院学报, 2008, 31(5): 671-678. [YAN G H, LI Q P, LYU D H. Climate change and future trends of the farming-grazing zone in Northern China. Journal of Nanjing Institute of Meteorology, 2008, 31(5): 671-678.]

[8] 陈晓晨, 徐影, 许崇海, 等. CMIP 5 全球气候模式对中国地区降水模拟能力的评估.气候变化研究进展, 2014, 10(3): 217-225. [CHEN X C, XU Y, XU C H, et al. Assessment of precipitation simulations in China by CMIP5 multi-models. Advances in Climate Change Research, 2014, 10(3): 217-225.]

[9] 莫兴国, 胡实, 卢洪健, 等. GCM 预测情景下中国 21 世纪干旱演变趋势分析. 自然资源学报, 2018, 33(7): 1244-1256. [MO X G, HU S, LU H J, et al. Drought trends over the terrestrial China in the $21^{\text {st }}$ century in climate change scenarios with ensemble GCM projections. Journal of Natural Resources, 2018, 33(7): 1244-1256.]

[10] TAYLOR K E, STOUFFER R J, MEEHL G A. An overview of CMIP 5 and the experiment design. Bulletin of the American Meteorological Society, 2012, 93(4): 485-498.

[11] 胡芩, 姜大膀, 范广洲. 青藏高原未来气候变化预估: CMIP 5 模式结果. 大气科学, 2015, 39(2): 260-270. [HU Q, JIANG D B, FAN G Z. Climate change projection on the Tibetan Plateau: Results of CMIP 5 models. Chinese Journal of Atmospheric Sciences, 2015, 39(2): 260-270.] 
[12] 刘彩红, 余锦华, 李红梅. RCPs 情景下未来青海高原气候变化趋势预估. 中国沙漠, 2015, 35(5): 1353-1361. [LIU C H, YU J H, LI H M. Projected climate change under the RCPs scenario in the Qinghai Plateau. Journal of Desert Research, 2015, 35(5): 1353-1361.]

[13] 吴蔚, 穆海振, 梁卓然, 等. CMIP 5 全球气候模式对上海极端气温和降水的情景预估. 气候与环境研究, 2016, 21(3): 269-281. [WU W, MU H Z, LIANG Z R, et al. Projected changes in extreme temperature and precipitation events in Shanghai based on CMIP 5 simulations. Climatic and Environmental Research, 2016, 21(3): 269-281.]

[14] 国家气候中心. 中国地区气候变化预估数据网. http: //www.climatechange-data.cn/en/. 2012. [National Climate Center. Climate change forecast data website in China. http: //www.climatechange-data.cn/en/. 2012.]

[15] ZOU L W, ZHOU T J. Near future (2016-40) summer precipitation changes over China as projected by a Regional Climate Model (RCM) under the RCP 8.5 emissions scenario: Comparison between RCM downscaling and the driving GCM. Advances in Atmospheric Sciences, 2013, 30(3): 806-818.

[16] HE C Y, ZHAO Y Y, HUANG Q X, et al. Alternative future analysis for assessing the potential impact of climate change on urban landscape dynamics. Science of the Total Environment, 2015, 532(5): 48-60.

[17] 景丞, 陶辉, 王艳君, 等. 基于区域气候模式 CCLM 的中国极端降水事件预估. 自然资源学报, 2017, 32(2): 266-277. [JING C, TAO H, WANG Y J, et al. Projection of extreme precipitation events in China based on regional climate model CCLM. Journal of Natural Resources, 2017, 32(2): 266-277.]

[18] 赵哈林, 赵学勇, 张铜会, 等. 北方农牧交错带的地理界定及其生态问题. 地球科学进展, 2002, 17(5): 739-747. [ZHAO H L, ZHAO X Y, ZHANG T H, et al. Boundary line on agro-pasture zigzag zone in North China and its problems on eco-environment. Advances in Earth Science, 2002, 17(5): 739-747.]

[19] 杜鹏飞, 姜洪涛, 袁小宇. 北方农牧交错带不同土地利用方式下表层土壤含水量对比研究. 干旱区资源与环境, 2009, 23(9): 118-122. [DU P F, JIANG H T, YUAN X Y. The research on top soil moisture content in different land use in transitional zone of pastures and farmlands in North China. Journal of Arid Land Resources and Environment, 2009, 23(9): 118-122.]

[20] 史培军, 孙劭, 汪明, 等. 中国气候变化区划(1961-2010年). 中国科学: 地球科学, 2014, 44: 2294-2306. [SHI P J, SUN S, WANG M, et al. Climate change regionalization in China (1961-2010). Science China: Earth Sciences, 2014, 44: 2294-2306.]

[21] VUUREN D P V, EDMONDS J, KAINUMA M, et al. The representative concentration pathways: An overview. Climatic Change, 2011, 109(1-2): 5 .

[22] 吴其重, 冯锦明, 董文杰, 等. BNU-ESM 模式及其开展的 CMIP 5 试验介绍. 气候变化研究进展, 2013, 9(4): 291294. [WU Q Z, FENG J M, DONG W J, et al. Introduction of the CMIP 5 experiments carried out by BNU-ESM. Advances in Climate Change Research, 2013, 9(4): 291-294.]

[23] CHYLEK P, LI J, DUBEY M K, et al. Observed and model simulated $20^{\text {th }}$ century Arctic temperature variability: Canadian Earth System Model CanESM 2. Atmospheric Chemistry \& Physics, 2011, 11(8): 22893-22907.

[24] PEACOCK S. Projected twenty-first-century changes in temperature, precipitation, and snow cover over North America in CCSM 4. Journal of Climate, 2012, 25(25): 4405-4429.

[25] DUFRESNE J L, FOUJOLS M A, DENVIL S, et al. Climate change projections using the IPSL-CM 5 Earth System Model: From CMIP 3 to CMIP 5. Climate Dynamics, 2013, 40(9-10): 2123-2165.

[26] STEVENS B, GIORGETTA M, ESCH M, et al. Atmospheric component of the MPI-M Earth System Model: ECHAM 6. Journal of Advances in Modeling Earth Systems, 2013, 5(2): 146-172.

[27] YUKIMOTO S, ADACHI Y, HOSAKA M, et al. A new global climate model of the meteorological research institute: MRICGCM 3 model description and basic performance. Journal of the Meteorological Society of Japan. ser. i, 2012, 90(2): $23-64$.

[28] BENTSEN M, BETHKe I, DEBERNARD J B, et al. The Norwegian Earth System Model, NorESM1-M - Part 1: Description and basic evaluation. Geoscientific Model Development, 2013, 6(3): 687-720.

[29] GIORGI F, COPPOLA E, SOLMON F, et al. RegCM 4: Model description and preliminary tests over multiple CORDEX domains. Climate Research, 2012, 52(1): 577.

[30] 艾梦池, 程效军. 数字影像重采样方法实现及对比分析. 辽宁工程技术大学学报: 自然科学版, 2015, 34(12): 13821387. [AI M C, CHENG X J. Implementation and comparison of VC-based resampling method for digital image analysis. Journal of Liaoning Technical University: Natural Science, 2015, 34(12): 1382-1387.]

[31] EGAN P J, MULLIN M. Recent improvement and projected worsening of weather in the United States. Nature, 2016, 
532(7599): 357-360.

[32] 张冬峰, 高学杰, 罗勇, 等. RegCM 4.0 对一个全球模式 20 世纪气候变化试验的中国区域降尺度: 温室气体和自然 变率的贡献. 科学通报, 2015, 60(17): 1631-1642. [ZHANG D F, GAO X J, LUO Y, et al. Downscaling a $20^{\text {th }}$ century climate change of a global model for China from RegCM 4.0: Attributable contributions of greenhouse gas emissions and natural climate variability. Chinese Science Bulletin, 2015, 60(17): 1631-1642.]

[33] 刘立涛, 刘晓洁, 伦飞, 等. 全球气候变化下的中国粮食安全问题研究. 自然资源学报, 2018, 33(6): 927-939. [LIU L T, LIU X J, LUN F, et al. Research on China's food security under global climate change background. Journal of Natural Resources, 2018, 33(6): 927-939.]

[34] 翟盘茂, 刘静. 气候变暖背景下的极端天气气候事件与防灾减灾. 中国工程科学, 2012, 14(9): 55-63, 84. [ZHAI P M, LIU J. Extreme weather/climate events and disaster prevention and mitigation under global warming background. Engineering Sciences, 2012, 14(9): 55-63, 84.]

\title{
Climate change and future trends in the Agro-Pastoral Transitional Zone in Northern China:
}

\section{The comprehensive analysis with the historical observation and the model simulation}

\author{
FANG Zi-hang ${ }^{1,2}$, HE Chun-yang ${ }^{1,2}$, LIU Zhi-feng ${ }^{1,2}$, ZHAO Yuan-yuan ${ }^{3}$, YANG Yan-jie ${ }^{1,2}$ \\ (1. Center for Human-Environment System Sustainability, State Key Laboratory of Earth Surface Processes and \\ Resource Ecology, Beijing Normal University, Beijing 100875, China; 2. School of Natural Resources, Faculty \\ of Geographical Science, Beijing Normal University, Beijing 100875, China; 3. School of Soil and Water \\ Conservation, Beijing Forestry University, Beijing 100083, China)
}

\begin{abstract}
The Agro-Pastoral Transitional Zone in Northern China (APTZNC) is one of the major regions of the ecological protection in China due to its sensitivity to climate change. Our objective was to understand the trend of the climate change in the APTZNC. The historical climate change from 1971 to 2015 and the future climate change from 2006 to 2050 in the APTZNC were analyzed by using the historical data and the simulated data. The climate change in the APTZNC showed a warm-dry trend from 1971 to 2005, with the annual average temperature rise by $0.39{ }^{\circ} \mathrm{C} / 10$ a and the annual average precipitation decrease by $4.60 \mathrm{~mm} / 10$ a. From 2006 to 2050, the regional climate change will show a warm-humid trend. The annual average temperature will increase by $0.20-0.50{ }^{\circ} \mathrm{C} / 10$ a, and the annual precipitation will increase by $1.49-15.59 \mathrm{~mm} / 10 \mathrm{a}$. We also found that the regional climate system will be unstable if the greenhouse gas emissions were not controlled. From 2006 to 2050, along with the increase of greenhouse gas emission concentration, the regional warming rate will increase from $0.25{ }^{\circ} \mathrm{C} /$ 10 a to $0.48{ }^{\circ} \mathrm{C} / 10 \mathrm{a}$, and the precipitation change rate will increase from $3.97 \mathrm{~mm} / 10$ a to 14.58 $\mathrm{mm} / 10 \mathrm{a}$. Therefore, we suggested that effective measures for mitigation and adaptation to the climate change are needed to guarantee the sustainable development of the APTZNC.
\end{abstract}

Keywords: climate change; Argo- Pastoral Transitional Zone in Northern China; historical observation; model simulation; mitigation and adaptation 